\title{
REFLEXÕES SOBRE OS MULTILETRAMENTOS E AS TICS: CONTRIBUIÇÕES PARA A EDUCAÇÃO A DISTÂNCIA
}

\author{
Reflections on the Multiliteracies and ICTs: Contributions to Distance Education
}

\author{
Adriana Cristina Sambugaro de Mattos BRAHIM, UNINTER ${ }^{1}$ \\ Edna Marta Oliveira da SILVA, UNINTER ${ }^{2}$
}

\begin{abstract}
Resumo: O objetivo deste trabalho é apresentar algumas reflexões sobre as contribuições do conceito de multiletramentos e do uso das tecnologias de informação e comunicação (TICs) na modalidade de Educação a Distância (EAD). Para a apresentação dessas reflexões pretende-se considerar os pressupostos teóricos advindos das teorias de letramento, mais especificamente dos multiletramentos. A associação de imagens, áudio e vídeo, com ou sem textos escritos, especialmente com as TICs, passam a exigir novas formas de letramento dos seus usuários, uma vez que a construção de significados ocorre por meio de modos variados (multimodais). Em outras palavras, as TICs conduzem as reflexões sobre letramento, ampliando o conceito para os multiletramentos, considerados fundamentais para os processos de ensino e de aprendizagem na contemporaneidade em todos os níveis, justamente por considerar o impacto advindo da utilização dos recursos tecnológicos que têm desencadeado novos olhares para o espaço da educação a distância.
\end{abstract}

PALAVRAS-CHAVE: educação a distância; multiletramentos; TICs; linguagem; comunicação.

\begin{abstract}
This paper aims to present some reflections on the contributions of the multiliteracy concept and the use of information and communication technologies ( ICTs) in the distance education modality. For the presentation of these reflections, it is intended to consider the theoretical assumptions originated from literacy theories, more specifically from multiliteracies. The association of images, audio and video, with or without written texts, especially with the ICTs, new ways of literacy of their users are required, once the construction of meanings begins to happen by means of varied modes (multimodalities). In other words, the ICTs lead to reflections on literacy, expanding the concept to the multiliteracies regarded as fundamental to the teaching and learning processes in the contemporary world at all levels, precisely by considering the impact resulting from the use of technological resources that has triggered new visions for the distance education area.
\end{abstract}

KEY WORDS: distance learning; multiliteracies; ICTs; language;communication.

\footnotetext{
${ }^{1}$ Doutora em Linguística Aplicada pela UNICAMP (2008).

2 Especialista em Ensino de Línguas Estrangeiras Modernas pela Universidade Tecnológica Federal do Paraná (2008)
} 


\section{INTRODUÇÃO}

A nossa relação com o mundo exterior ocorre graças aos recursos dos nossos cinco sentidos: tato, paladar, olfato, visão e audição. Ainda que cada um deles possua sua função específica, é por meio da visão e da audição, principalmente, que apreendemos as informações e transmitimos ideias. São esses dois sentidos, basicamente, que nos permitem concretizar aquilo que denominamos comunicação e linguagem humanas.

Ao voltarmos no tempo, na pré-história da humanidade, podemos encontrar os primeiros índicos de comunicação e linguagem entre os povos mais primitivos. É impossível não nos lembrarmos das pinturas rupestres, como as de Lascaux. Imagens registradas nas paredes das cavernas, retratando a vida daqueles primeiros homens, já eram utilizadas com fins comunicativos. E isso antes mesmo da criação dos primeiros códigos orais ou escritos. As pinturas rupestres constituíam os registros do mundo daquela época, sob a ótica dos homens pré-históricos (WOHLGEMUTH, 2005, p. 13).

A necessidade do ser humano em exteriorizar necessidades e sentimentos já estava presente nessas primeiras formações sociais. Os registros rupestres davam conta, até certo ponto, de expressar algo que, anteriormente, era somente gestual e cuja comunicação só poderia ser realizada entre duas ou mais pessoas (WOHLGEMUTH, 2005 , p. 14). Sobre a comunicação humana, Wohlgemuth (2005, p. 13-14) aponta para a longa trajetória evolutiva pela qual os seres humanos têm passado. A cada nova forma de comunicar ideias, sentimentos e pensamentos, a civilização se transforma. Segundo o autor, podem ser identificadas quatro etapas dessa evolução. Na primeira etapa, a da exteriorização, o corpo humano era o veículo de comunicação; na segunda etapa, a das linguagens de transposição, ocorreu a revolucionária inclusão da escrita fonética paralelamente aos desenhos, pinturas e música; na terceira etapa, a da amplificação, surgiram a imprensa, as transmissões via satélite e as gravações de áudio e vídeo; por último, na quarta etapa, que o autor denomina comunicação individual, foram criadas novas linguagens e meios de comunicação, como a internet. Ou seja, gestos, expressões corporais, imagens e sons foram incorporados à comunicação, permitindo ao ser humano expressar ideias e sentimentos que até então não eram possíveis de serem exteriorizados. Como Wohlgemuth (2005, p. 15) afirma "a linguagem verbal (...) fez do ser humano um comunicador. (...) Comunicar já não era mais uma função instintiva como a de caçar ou comer, mas uma função cultural". 
Somos, portanto, seres de linguagem. A linguagem pode ser entendida como um panorama mais geral do qual faz parte a diversidade das línguas naturais (PETTER, 2007, p. 13). Mas é para a língua - expressa pela linguagem oral ou escrita - que se confere um valor de exclusividade da fonte do saber humano. À língua é atribuída a supremacia do conhecimento e da interpretação do mundo, conforme afirma Santaella (1983, p. 2). Para a autora,

O saber analítico, que essa linguagem ${ }^{3}$ permite, conduziu à legitimação consensual e institucional de que esse é o saber de primeira ordem, em detrimento e relegando para uma segunda ordem todos os outros saberes, mais sensíveis, que as outras linguagens, as não verbais, possibilitam (SANTAELLA, 1983, p.2).

A supremacia da língua, portanto, pode ser considerada aparente e não invalida o poder de comunicação de outras formas de linguagem. Mesmo com organização dos códigos orais e escritos, a comunicação entre os homens não deixou à parte o recurso visual. Ao contrário, integrou-o. Isso pode ser claramente observável em nossa sociedade atual que faz uso dos mais variados elementos visuais em larga escala e nos mais diversos segmentos como instrumento de comunicação. Essa é uma herança ancestral.

Imagens estáticas ou em movimento fazem parte do nosso dia a dia, seja qual for a mídia utilizada para comunicar uma ideia. Somos a tal ponto bombardeados por mensagens visuais que isso "tem levado os apocalípticos da cultura ocidental a deplorar o declínio das mídias verbais" (SANTAELLA; NÖTH, 2008, p. 13). Não cabe aqui discutirmos a veracidade de tal "declínio". Entretanto, é claramente observável que, enquanto a palavra tem sido foco de estudo de gramáticos, filólogos e estudiosos de demais áreas afins, não se pode dizer a mesma coisa em relação aos estudos da imagem. Para Santaella e Nöth (2008, p.13), ainda há por ser institucionalizada uma ciência que dê conta de tal estudo. Por enquanto, faz-se necessário um trabalho interdisciplinar entre diversos campos do conhecimento humano para que o estudo da imagem se concretize. Entre as áreas apontadas pelos autores como aquelas que podem promover tal trabalho incluem-se as teorias de cognição, da semiótica visual e os estudos das mídias.

Desde tempos remotos, o homem se vale de sua inteligência para transformar os recursos disponíveis ao seu redor em ferramentas que garantam não somente a sua sobrevivência, mas também para a transmissão de informações e de conhecimentos

\footnotetext{
${ }^{3}$ Para Santaella (1983, p. 2), a língua é "uma forma de linguagem e meio de comunicação". Por isso, na citação, a referência está sendo feita a linguagem, num sentido mais amplo de comunicação (nota das autoras)
} 
adquiridos. Objetos e ferramentas feitos a partir de madeira, pedras e ossos deram lugar, no decorrer da história, à manufatura de produtos cada vez mais sofisticados que demandam processos igualmente mais elaborados para sua confecção. Isso somente foi possível a partir do surgimento de tecnologias de produção que permitiram ao homem automatizar processos que anteriormente eram, na sua essência, artesanais. Para Kenski (2007, p. 21), a evolução tecnológica em cada época é parte integrante da evolução social do homem. A tecnologia não está restrita somente à criação de artefatos; ela também altera o modo como vivemos e como nos comportamos. As tecnologias de comunicação e informação (doravante, TICs) podem ser um bom exemplo disso. Segundo Costa (2008, p. 1), com o advento das TICs, o mundo digital "colocou a linguagem visual em evidência" e, como consequência, emprega o uso de "textos que apresentam duas ou mais modalidades semióticas em sua composição”. As TICs revolucionaram a forma de nos comunicarmos e interagirmos com o outro, pois permitem o uso de imagens estáticas ou em movimento, associadas a textos escritos e/ou de áudio, com transmissão e divulgação imediata para qualquer ponto do planeta ao simples "clique" de um mouse.

Em todos os segmentos da sociedade, é notória a presença de artefatos tecnológicos, conforme afirma Bastos $^{4}$ (2000 apud BRITO e PURIFICAÇÃO, 2006, p.18), e isso justificaria a presença da tecnologia também dentro do espaço escolar. Para Brito e Purificação (2006, p. 22), o uso das tecnologias pela comunidade escolar "viabiliza uma formação intelectual, emocional e corporal do cidadão que lhe permita criar, planejar e interferir na sociedade". O espaço escolar caracteriza-se como um polo difusor de artefatos facilitadores do processo de ensino e aprendizagem, tais como a lousa, o giz e o próprio material didático. No entanto, foi com o advento da internet e dos recursos disponível na web que caíram por terra os limites físicos impostos por um único ambiente, com espaço físico limitado, tal como é a sala de aula. A internet extrapola as dimensões do espaço-tempo de uma aula convencional, uma vez que é possível a comunicação entre pessoas situadas nos mais diferentes lugares e a qualquer hora. Basta somente que haja um computador com acesso à rede.

Toda essa revolução tecnológica relacionada às novas formas de transmissão de informação e de conhecimentos implicou também em mudanças na relação entre professores e alunos. $\mathrm{O}$ papel do(a) professor(a) como o(a) detentor(a) do

\footnotetext{
${ }^{4}$ BASTOS, J. A. A. (Org). Educação Tecnológica: Imaterial \& Comunicativa. Curitiba: Cefet-PR, 2000. Coletânea Educação \& Tecnologia.
} 
conhecimento sofre um deslocamento, pois ele(a) deixa de ser aquele(a) que "sabe tudo" para tornar-se um membro a mais do grupo em busca da aprendizagem. Pode-se, então, afirmar que o novo e grande paradigma da educação do século XXI é o da redefinição de papéis nas relações e processos de ensino e aprendizagem.

No panorama que se apresenta e, uma vez que as TICs se fazem presentes nos processos de ensino e aprendizagem, tanto em cursos totalmente a distância quanto em cursos presenciais, pode-se questionar até que ponto o simples conhecimento das técnicas de utilização das TICs é o suficiente para que o(a) professor(a) cumpra o seu papel na mediação do processo de construção do conhecimento dentro do espaço escolar. Tal questionamento surgiu a partir do contato e da docência das autoras deste trabalho em cursos na modalidade de EAD em uma instituição de ensino superior da cidade de Curitiba - Paraná. Pode-se também perguntar se não seria necessário que o(a) professor(a) de cursos na modalidade de EAD refletisse a respeito do modo como suas aulas acontecem na modalidade presencial, utilizando-se de quadro, giz, datashow ou outro tipo de recurso, seja eletrônico ou não. É pertinente questionar se a forma de ensinar presencialmente também seria adequada ao novo espaço de aprendizagem a distância no qual são utilizados recursos tecnológicos associados a imagens, sons, vídeos e textos simultaneamente, além de não contar com a presença física dos alunos. Se entendermos que a comunicação entre seres humanos ocorre por meio da linguagem, podemos questionar quais seriam as consequências da inclusão das TICs, em processos de ensino e aprendizagem em cursos cuja modalidade é a distância, uma vez que as informações, antes limitadas a textos escritos são, agora, também veiculadas por meio de textos multimodais ${ }^{5}$.

Portanto, há de ser verificado se a mesma prática instrucionista, muitas vezes presente na educação presencial, não estaria sendo usada ou transferida para a EAD. E, se isso ocorre, se deveria, então, pensar qual caminho ou qual formação é necessária a um(a) professor(a) (e igualmente para os aprendentes) para dar conta de mídias tão diversas. Além disso, faz-se necessária a análise de como esses aspectos deveriam ser trabalhados nas instituições de ensino superior que oferecem cursos na modalidade a distância.

Encontramos na literatura sobre EaD uma grande preocupação com a formação

\footnotetext{
${ }^{5}$ Neste contexto, utilizaremos a definição de "multimodais" proposta por Costa (2008, p.1). Segundo a autora, "textos que apresentam duas ou mais modalidades semióticas em sua composição tomaram o lugar das tradicionais práticas da escrita, provocando efeitos nos formatos e nas características desses textos, resultando no que foi denominado multiletramentos ou multimodalidades."
} 
do(a) professor(a)-tutor(a), ou do orientador acadêmico. Segundo alguns autores (como MACHADO \& MACHADO, 2004; BRUNO \& LEMGRUBER, 2009), é ele o responsável pelo processo de mediação pedagógica do conhecimento, por meio dos vários papéis que assume no contexto da educação a distância.

Mattar (2012), por exemplo, ao trazer os diferentes papéis desenvolvidos pelo tutor, determinados por algumas instituições (papel administrativo e organizacional; papel social; papel pedagógico e intelectual; papel tecnológico) afirma que, pelo acúmulo de atividades que podem ser exigidas, há uma precarização do trabalho docente do tutor. Essa situação pode ser observada em diversas instituições de ensino, públicas ou particulares, nas quais há uma fragmentação do trabalho docente em que as tarefas são realizadas por diferentes pessoas. Observa-se, então, que dada a complexidade da EaD, o(a) professor(a) tem que ter habilidades e competências diferenciadas.

Outro aspecto importante a ressaltar, claramente colocado por Mattar (2012, p. 01) é que as funções do(a) professor (a) (tutor/a) vão depender, muito fortemente, do modelo pedagógico adotado pela instituição de ensino. Em outras palavras, o modelo de $\mathrm{EaD}$ vai determinar as funções do(a) professor(a). Assim, as funções do(a) professor(a) que trabalha em cursos na modalidade de EaD podem estar de acordo com diferentes modelos pedagógicos. Nesse sentido, dependendo do modelo adotado, a mediação pedagógica pode nem chegar a acontecer, pois, nos últimos anos, as funções do trabalho docente têm sido aprimoradas ou desenvolvidas para ações que levem a uma concepção mais contemporânea de $\mathrm{EaD}$ e que supere a EBAD - educação bancária a distância. Porém, percebe-se que muitos modelos adotados no Brasil ainda hoje não trazem como base de suas propostas a concepção de educação como produção de conhecimentos. Esse aspecto influencia, obviamente, o estabelecimento das funções do(a) professor(a) da EaD. Assim, conforme aponta Bruno e Lemgruber (2009), os próprios "Referenciais de Qualidade para Cursos a Distância” apresentam como principal atribuição do(a) tutor(a) o "esclarecimento de dúvidas", ou seja, o modelo é conteudista e "a aula é dada pelo conteúdo, e o aluno tem que se virar sozinho, ou com o mínimo de suporte e interação". Esse modelo adotado parte de uma concepção fordista de EaD que teve suas origens nas décadas de 1960 e 1970 quando características industriais como divisão de trabalho, economia de escala e produção em massa influenciaram o desenvolvimento de um processo de aprendizagem mecanizado e linear (MARTINS, 2012, p. 135) e um processo de ensino igualmente padronizado, formalizado, otimizado e racionalizado. 
Esse modelo determinou uma divisão do trabalho docente na $\mathrm{EaD}$ e é por isso que, na literatura, encontramos o trabalho do(a) tutor(a) como, em muitos casos, diferente do trabalho do(a) professor(a)-regente ou do(a) professor(a)-conferencista. Este(a) último(a) é quem ministra as aulas, transmitidas ao vivo ou gravadas, e dificilmente trabalha nas atividades tutoriais, pois a função de dar orientação ou responder questionamentos dos alunos não é, na maioria das vezes, tarefa do(a) professor(a)-regente ou professor(a)-conferencista. A ele(a) cabe apenas a "transmissão" das informações ou dos conhecimentos da disciplina.

Ainda para Mattar (2012), o neofordismo superou este modelo fordista, envolvendo "alta inovação no produto e alta variabilidade nos processos, mas ainda com pouca responsabilidade dos empregados". Nesse modelo, são produzidos cursos menores e que podem ser atualizados constantemente. Os professores passam a fazer parte de grupos de trabalho que são responsáveis por todas as etapas: planejamento, design, produção, distribuição, avaliação e acompanhamento continuado do curso. Em outras palavras, conforme posto por Mattar, "no fordismo o professor (agora definido não mais como tutor, mas como professor online) não produz o material que deve utilizar em suas atividades de ensino, no neo e pós-fordismo o professor é o autor e/ou organizador do material que utiliza como docente". Para o mesmo autor, "enquanto o fordismo estaria associado ao behaviorismo, o neofordismo e o pós fordismo estariam associados ao construtivismo - e diversas teorias dele derivadas". O autor sugere, então, modelos alternativos de $\mathrm{EaD}$ que estão pautados na teoria construtivista de aprendizagem - que tem como base o foco da educação no processo e não no conteúdo para assim superar a concepção fordista que divide o trabalho docente. Esses modelos vão, consequentemente, mudar as funções desempenhadas pelo(a) orientador(a) acadêmico(a), pois junto com o desenvolvimento de novas tecnologias de comunicação e interação, vão determinar um modelo de $\mathrm{EaD}$ com mais atividades interativas e participativas que superarão o modelo de estudo autônomo, independente e ultrapassado. Para Bruno e Lemgruber (2009, p. 02), este novo cenário da EaD

implica em que o professor assuma múltiplas funções, se integre a uma equipe multidisciplinar e assuma-se como: formador, conceptor ou realizador de cursos e de materiais didáticos, pesquisador, mediador, orientador e, nesta concepção, assumir-se como recurso do aprendente. 
Para que assuma essas múltiplas funções, as autoras deste trabalho sugerem algumas características que devem compor o perfil adequado para o(a) orientador(a) acadêmico(a): possuir formação superior e adequada à área do conhecimento em que atua; ter experiência profissional em formação acadêmica; articular teoria e prática educativa de forma crítica; ter familiaridade, desenvoltura e estar aberto(a) a aprender sempre a lidar com as ferramentas tecnológicas de interação e comunicação; ter empatia e estar sempre disposto(a) a interagir com os aprendizes; ter conhecimento das características da andragogia; ter clareza dos desafios e da complexidade da educação a distância; ser cooperativo(a); ter habilidades para trabalhar em equipe; ter espírito investigativo e gostar de fazer pesquisa; ter espírito receptivo para a formação permanente; ser criativo(a) e ter habilidades para planejar a mediação pedagógica tutorial

Conclui-se, assim, que a partir de uma concepção mais contemporânea de $\mathrm{EaD}$, em modelos construtivistas, o papel do(a) professor(a) é mediar pedagogicamente a aprendizagem e a construção de conhecimentos. De acordo com Silva (2010, p. 221), "de polo transmissor, ele passa a agente provocador de situações, arquiteto de percursos, mobilizador da inteligência coletiva”. Ou, em outras palavras, ele(a) passa a ser, como afirma Leal (2004, p. 25),

\footnotetext{
um educador a distância. Aquele que coordena a seleção de conteúdos, que discute as estratégias de aprendizagem, que suscita a criação de percursos acadêmicos, que problematiza o conhecimento, que estabelece o diálogo com o aluno, que media problemas de aprendizagem, sugere, instiga, acolhe. Enfim, um professor no espaço virtual.
}

Além disso, o(a) professor(a) na EaD é o personagem do processo que vai caracterizar a presença a distância (POSSARI, 2010) e suas funções, em modelos mais contemporâneos de $\mathrm{EaD}$, vão muito além de um(a) tutor(a) que tira dúvidas, que envia avisos de prazo de entrega de atividades, avisos motivacionais quando percebe que o aprendiz não tem participado das atividades propostas; que posta no AVA as atividades que outro(a) professor(a) elaborou. $\mathrm{O}$ (a) professor(a) passa a assumir verdadeiramente a função docente e deve estar preparado(a) para um nova perspectiva de $\mathrm{EaD}$ a partir da qual estabelece-se um novo cenário no qual faz-se necessário conviver com novos personagens e realizar novas atividades. 


\section{DESENVOLVIMENTO}

Ainda que a modalidade de ensino a distância já fosse usada muito antes do século $\mathrm{XX}$, foi com o advento das TICs que ocorreu a sua maior expansão. Com a revolução promovida pelas TICs - mais especificamente, com a internet - as relações humanas, sociais e culturais alteraram significativamente a nossa forma de interagir com os outros e com o mundo.

Uma vez que mudamos a forma de nos relacionarmos com outras pessoas e com a informação, é necessário refletir a respeito da necessidade de novas formas de se pensar a educação. Para Lyotard (1998, 1993 apud KENSKI, 2007, p. 18) o homem está passando, na atualidade, por seu maior desafio que é a tecnologia. Com isso, o autor sugere que a adaptação do homem ao movimento do mundo passa pela sua adaptação a todos e quaisquer avanços tecnológicos. Kenski (2007, p. 18) completa a ideia do autor ao incluir aí a educação. Para a autora, "este é também o duplo desafio para a educação: adaptar-se aos avanços das tecnologias e orientar o caminho de todos para o domínio e apropriação crítica desses novos meios". Se levarmos tal afirmação para situações de ensino e aprendizagem que ocorrem em cursos de EAD, essa modalidade de ensino acaba por apresentar um movimento que obriga a academia e os educadores em geral a pensar como a educação e, mais especificamente, as práticas pedagógicas, podem ou devem acontecer por meio dos novos recursos trazidos com o desenvolvimento das TICs.

De uma forma crítica, Demo (2007, p. 92) traz esta reflexão ao afirmar que "quando a escola/universidade não sabe ler o mundo ou mantém estratégias ultrapassadas para lidar com o mundo, este lhes escapa, deixando para os alunos a sensação de vazio para sempre" e nada "ou quase nada" aprendem, muito menos aprendem a aprender.

Em relação à reflexão sobre uma formação mais adequada para o processo de ensino e aprendizagem na EAD, o que se pode verificar é que o domínio das práticas convencionais de leitura e escrita não dá mais conta do universo de diversidades linguísticas ofertadas pelos LMS (Learning Management System), por exemplo. Conforme afirma Braga (2013, p. 41), 


\begin{abstract}
Não podemos ignorar que a interação com as máquinas digitais demanda muito mais que aprender a gerenciar as operações de comandos (isso, por si só, um pesadelo inicialmente enfrentado pelos imigrantes digitais). Há também mudanças significativas nos modos de ler e produzir textos. Em meios digitais, estamos todos imersos em enunciados multissemióticos e hipertextuais. Nas páginas digitais da internet a leitura é multimodal e demanda escolhas de percursos e o acesso a conteúdos é realizado em rede, acessando links que remetem a outras páginas e a outros links.
\end{abstract}

Assim, com a inclusão de imagens, áudio e vídeo, além do texto escrito, passa a ser exigido dos alunos (e também dos professores) de cursos que utilizam ferramentas da internet, novas formas de letramento, pois a construção de significados ocorre por meio de modos variados (multimodais). Em outras palavras, conforme salienta Rojo (2013, p. 8), "se os textos da contemporaneidade mudaram, as competências/capacidades de leitura e produção de textos exigidas para participar de práticas de letramento atuais não podem ser as mesmas”. Coloca-se, então, como um grande, mas necessário desafio, compreender os textos da hipermídia, os gêneros multissemióticos. É nesse contexto que se coloca o conceito de novos letramentos ou multiletramentos, oriundo justamente a partir de uma ampliação do conceito de letramento ${ }^{6}$ proposto na década de 1980 . O conceito de multiletramentos é, portanto, utilizado para referir-se ao uso social da leitura e da escrita, não se restringindo somente às práticas advindas da aprendizagem da escrita.

A proposição do termo "multiletramentos" foi feita pela primeira vez pelo Grupo de Nova Londres (New London Group - NLG), em 1996. De acordo com Rojo (2013, p. 14) o objetivo do grupo foi justamente apontar, por meio do prefixo "multi", para dois tipos de "múltiplos": as práticas de letramento contemporâneas trazem a preocupação do uso da multiplicidade de linguagens, semioses e mídias envolvidas na criação de significação para os textos multimodais contemporâneos e também "a pluralidade e a diversidade cultural trazidas pelos autores/leitores contemporâneos a essa criação de significação". Assim, o projeto dos multiletramentos proposto pelo NLG (New London Group, 2006[1996]) e por Cope e Kalantzis (2006, apud ROJO, 2013), propõe uma grade analítica para as modalidades linguística, visual, espacial, gestual e sonora, conforme representação a seguir.

Na figura 1, observa-se a caracterização modal, a partir do sentido de

\footnotetext{
6 Para Soares $(2009$, p. 39), letramento é o "resultado da ação de ensinar e aprender as práticas sociais de leitura e escrita; o estado ou condição que adquire um grupo social ou um indivíduo como consequência de ter-se apropriado da escrita e de suas práticas sociais".
} 
"modalidade" ou "modo", utilizado para refletir diferentes qualidades de percepção sensorial provocadas por diversas formas de produção de sentidos em que envolvem, segundo Rojo (2013, p. 23), tecnologias diferenciadas.

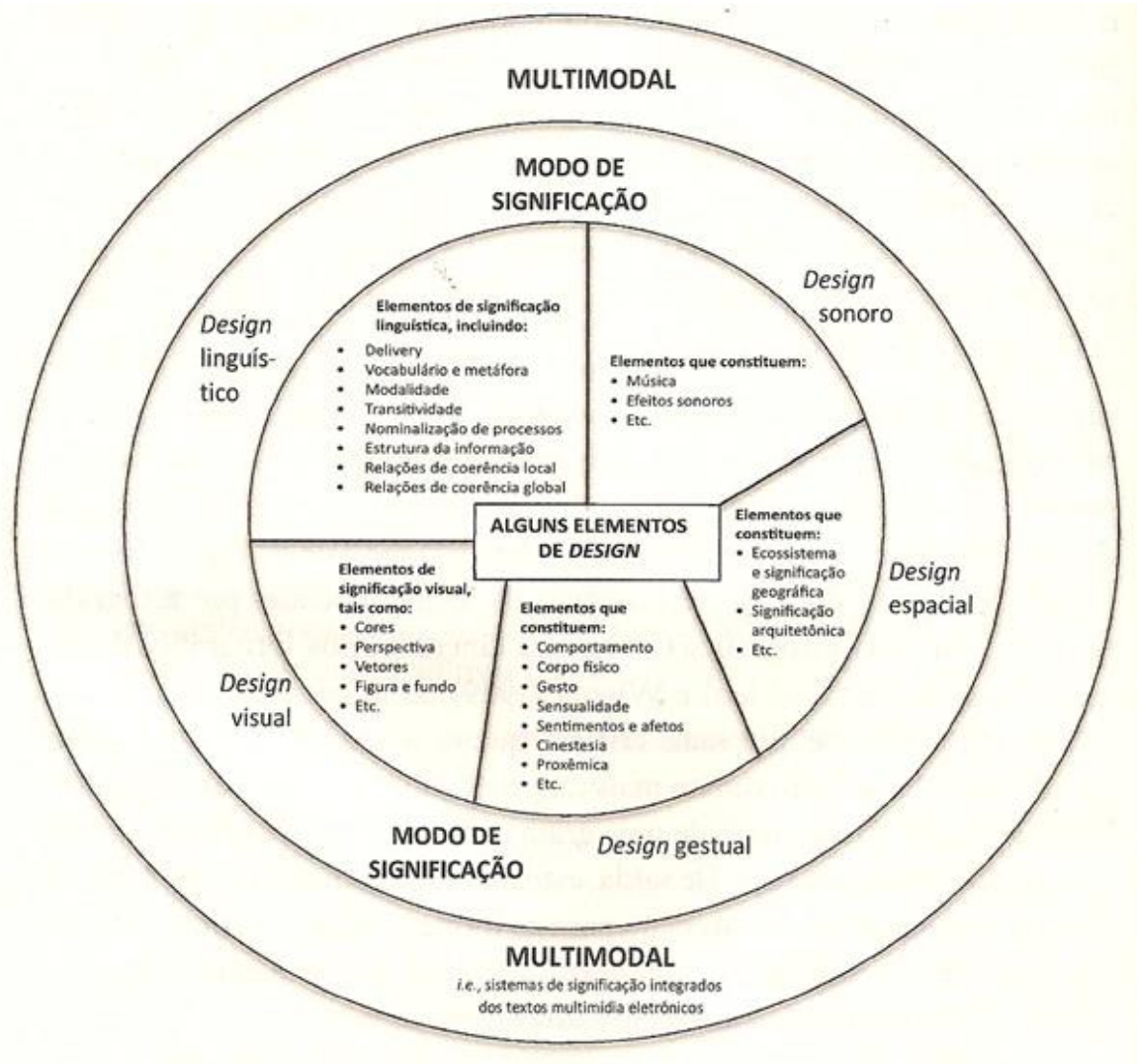

Figura 1. Os sistemas multimodais e seus elementos a serem considerados (adaptada de Grupo de Nova Londres, 2006 [1996]: 26 apud ROJO, 2013, p. 24)

A multimodalidade presente nos recursos empregados nas TICs implica, portanto, em práticas de letramento diferenciadas adaptadas ao mundo digital. A escola, ainda que imersa em uma sociedade altamente tecnológica, está longe de dar conta de outros tipos de letramentos, além da escrita e da leitura (Rojo, 2013, p. 16). Sobre a importância da reflexão sobre os novos letramentos nas práticas de ensino e aprendizagem na EAD, Buzato (2013, p. 32) afirma:

É certo que os letramentos digitais desempenham um papel central nessas reflexões mais recentes, justamente porque eles permitem estruturar, representar e coordenar o tempo-espaço "dentro" e "através" de diversas atividades, de formas que perturbam profundamente a ilusão da unicidade e linearidade espaciotemporais na qual estão fundadas muitas de nossas práticas de letramento institucionalizadas, especialmente as escolares. Sem desconsiderar as maneiras como instituições, tradições, cânones e tecnologias (disciplinares) localizam os letramentos, pesquisadores dos novos letramentos têm tentado entender melhor como os (novos) letramentos deslocam e articulam textos, interesses, capacidades, subjetividades e 
tecnologias distribuídas espaciotemporalmente. Dito de outra forma, temos tentado trabalhar com uma concepção de letramentos como redes heterogêneas e dos contextos que os letramentos são estudados como espaços fronteiriços.

Observa-se, então, que o conceito de letramento amplia-se e os estudos sobre o tema trazem contribuições significativas para a EAD, especialmente no âmbito das TICs. Tais conceitos merecem ainda um estudo mais aprofundado. Por hora, é importante destacar que os textos multissemióticos trazidos para as atividades propostas com os recursos das TICs, necessitam, consideravelmente, de uma reflexão crítica sobre como se está preparando os partícipes do processo de ensino e aprendizagem em cursos a distância.

\section{CONSIDERAÇÕES FINAIS}

Algumas características da linguagem visual - veloz, analítica e sintética conferem ao ser humano uma propensão natural para o seu uso. Aliada à audição, a linguagem visual permite que grande parte das informações recebidas do mundo ao nosso redor possam ser não somente captadas, mas também compreendidas. A vida moderna está repleta dessas mensagens, inclusive no espaço acadêmico. Resulta, daí, sua relevância do uso de mensagens associadas a textos, sons e imagens como recursos pedagógicos em processos de ensino e de aprendizagem.

Tem sido uma discussão frequente, no espaço acadêmico, o impacto do uso das TICs como ferramentas facilitadoras do processo educacional. Para Gianolla (2002, p. 49) o espaço acadêmico é um grande difusor de novos saberes e sempre foi o local que se utilizou de diferentes recursos tecnológicos com objetivos pedagógicos.

Além disso, conforme afirma Kenski (2007), com o uso das TICs "a sala de aula se abre para o restante do mundo e busca novas parcerias e processos para ensinar e aprender" e isso fez com que surgisse uma nova relação entre professores e alunos. Essa nova relação é de fato o que tanto Paulo Freire (2000, p.11)) acreditou ser necessário para a educação em que alunos e professores aprendessem juntos, pois "não há docência sem discência".

Nesse sentido, a fim de que possa dar conta dos processos educacionais na $\mathrm{EaD}$, o (a) professor(a) tem o grande desafio de lidar com uma nova forma de pedagogia que as ferramentas tecnológicas exigem e, neste contexto, muito tem sido 
discutido sobre o processo de aprendizagem com o auxílio de LMS, por exemplo, e da própria internet. Mas o que se pode perceber é que ainda há aspectos que precisam ser repensados, como é o caso da importância da reflexão acerca de como podem ser propostas práticas adequadas à nova realidade do processo de ensino e de aprendizagem que se dá por meio do uso das TICs. Considera-se que um olhar sobre os multiletramentos é necessário e, por que não afirmar, condição essencial para que a EAD configure-se como modalidade na qual se instale, verdadeiramente, o paradigma contemporâneo da educação, ou seja, o da construção de conhecimentos.

\section{REFERÊNCIAS}

BRAGA, D. B. Ambientes Digitais: reflexões teóricas e práticas. São Paulo: Cortez, 2013.

BRITO, G. S.; PURIFICAÇÃO, I. Educação e Novas Tecnologias: Um Repensar. Curitiba: IBPEX, 2006.

BRUNO, A. R.; LEMGRUBER, M. S. Dialética professor-tutor na educação on-line: o curso de Pedagogia-UAB-UFJF em pespectiva. In: II Encontro Nacional sobre Hipertexto. Belo Horizonte, 29-31, 2009.

BUZATO, M.K. Tecnologia, espaciotemporalidade e educação: contribuições dos estudos sobre novos letramentos para uma reflexão sobre EaD e Universidade no Brasil. In: EaD em tela: docência, ensino e ferramentas digitais. São Paulo: Pontes, 2013.

COSTA, G. C. Mulitletramento Visual na Web. Disponível em: $<$ http://www.giseldacosta.com.br/public/6147108-Multiletramento-Visual-na-WEB-

UFPE.pdf > Acesso em 1 set. 2008.

DEMO, P. O porvir - desafio das linguagens do século XXI. Curitiba: Ibpex, 2007.

FREIRE, P. Pedagogia da Autonomia: Saberes Necessários à Prática Educativa. 15 Edição. São Paulo: Paz e Terra: 2000

GIANOLLA, R. Informática na Educação: Representações Sociais do Cotidiano. $3^{\text {a }}$ Edição. São Paulo: Cortez: 2002.

KENSKI, V. M. Educação e Tecnologias: O Novo Ritmo da Informação. $1^{a}$ Edição. Campinas. Papirus: 2007.

PETTER, M. Linguagem, língua, linguística. In: FIORIN, José Luiz (Org.). Introdução à Linguística I - Objetos teóricos. 5 ed. São Paulo: Contexto, 2007. p. 11-24.

LEAL, R. B. A importância do tutor no processo de aprendizagem a distância. Revista Iberoamericana de Educación, 2004. Disponível em: <http://www.rieoei.org/deloslectores/947Barros.PDF> Acesso em: 12 fev. 2014

MACHADO, L. D. e MACHADO, E. C. O PAPEL DA TUTORIA EM AMBIENTES DE EAD. Abril/2004. Disponível em: http://www.abed.org.br/congresso2004/por/htm/022-TC-A2.htm. Acesso: 20 de maio de 2012.

MARTINS, O. B. Trabalho Docente em EAD: Reflexão crítica da ação docente nesta modalidade de ensino. In: Oliani, G. e Moura, R. A. (orgs). Educação a Distância: gestão e docência. Curitiba: Editora CRV, 2012.

MATTAR, J. Tutoria e interação em educação a distância. São Paulo: Cengage Learning, 2012. 
POSSARI, L.H. V. Metodologia e produção de material didático em EaD. Curso de Especialização para docentes e orientadores acadêmicos em EaD. Curitiba: Facinter, 2010.

ROJO, R. (org.). Escola Conectada - os multiletramentos e as TICs. São Paulo: Parábola, 2013.

SANTAELlA, L. O que é Semiótica. São Paulo: Brasiliense, 1983. (Col. Primeiros Passos). Disponível em:

<http://pt.slideshare.net/producaoaudiovisualunip/livro-o-que-semitica-lucia-santaellaeditora-brasiliense> Acesso em 15 dez. 2013.

SANTAELLA, L.; NÖTH, W. Imagem: cognição, semiótica, mídia. $1^{\text {a }}$ ed. São Paulo: Iluminuras, 2008.

SILVA, M. Desenho didático: contribuições para a pesquisa sobre formação de professores para docência online. In: SILVA, Marco; PESCE, Lucila; ZUIN, Antônio (Orgs.). Educação online: cenário, formação e questões didático-metodológicas. Rio de Janeiro: Wak Editora, 2010.

SOARES, M. Letramento: um tema em três gêneros. 3a ed. Belo Horizonte: Autêntica, 2009. 124 p.

WOHLGEMUTH, J. Vídeo Educativo: Uma Pedagogia Audiovisual. Brasília:

SENAC, 2005. 